\title{
Systematic Review and Meta-Analysis of Liver Resection for Colorectal Metastases in Elderly Patients
}

\author{
Tim van Tuil ${ }^{a}$ Ali A. Dhaif ${ }^{b}$ Wouter W. te Riele ${ }^{a}$ Bert van Ramshorst ${ }^{a}$ \\ Hjalmar C. van Santvoort ${ }^{a}$ \\ ${ }^{a}$ Department of Surgery, St. Antonius Hospital, Nieuwegein, The Netherlands; ${ }^{b}$ Department of Surgery, \\ Salmaniya Medical Complex, Ministry of Health, Manama, Bahrein
}

\section{Keywords}

Liver · Surgery · Cancer postoperative morbidity and mortality were increased with higher age, liver resection for CRLM seems justified in selected elderly patients.

\begin{abstract}
Background: This systematic review and meta-analysis evaluated the short- and long-term outcomes of liver resection for colorectal liver metastases (CRLM) in elderly patients. Methods: A PubMed, EMBASE, and Cochrane Library search was performed from January 1995 to April 2017, for studies comparing both short- and long-term outcomes in younger and elderly patients undergoing liver resection for CRLM. Results: Eleven studies comparing patients aged $<70$ years with patients aged $>70$ years and 4 studies comparing patients aged $<75$ years with patients aged $>75$ years were included. Postoperative morbidity was similar in patients aged $>70$ years ( 27 vs. $30 \% ; p=0.35$ ) but higher in patients aged $>75$ years ( 21 vs. $32 \% ; p=0.001$ ). Postoperative mortality was higher in both patients aged $>70$ years $(2$ vs. $4 \% ; p=0.01$ ) and in patients aged $>75$ years ( 1 vs. $6 \%$; $p=0.02$ ). Mean 5 -year overall survival was lower in patients aged $>70$ years ( 40 vs. $32 \% ; p<0.001$ ) but equal in patients aged $>75$ years ( 42 vs. $32 \% ; p=0.06$ ). Conclusion: Although
\end{abstract}

(c) 2018 S. Karger AG, Basel

E-Mail karger@karger.com www.karger.com/dsu

\section{Introduction}

Colorectal cancer is one of the most common malignant tumours in the Western world, with about 1.2 million new cases every year [1]. Of these patients, about $50 \%$ develop liver metastasis any time after diagnosis [2-4]. Liver resection is currently the only treatment with curative intention in patients with colorectal liver metastases (CRLM), with an overall 5-year survival rate in the range of $30-40 \%[5,6]$.

Increased life expectancy means that potential cure becomes a more important outcome. The number of elderly patients who are potential candidates for CRLM is increasing. Elderly patients commonly present with other comorbidities, especially cardiovascular, as well as using multimedications and reduced physiological reserve. Any major operation in this age group is thus considered a high risk. 
Therefore, this specific population requires optimal treatment protocols due to the accompanying comorbidities. Surgical and anaesthetic techniques have improved significantly in the last 2 decades $[7,8]$. These improvements resulted in better short-term morbidity and mortality rates. Recently, several observational studies have suggested that liver resection for CRLM in elderly patients is a safe treatment with 5-year survival rates reaching up to $40 \%$ [9-12]. These studies are, however, difficult to interpret and compare due to limited numbers of patients in mostly the elderly group, differences in patient selection, and ambiguous definition of "elderly patients."

Recent systematic reviews and meta-analysis focussed only on short-term outcomes [13] and combined patients for both CRLM and hepatocellular carcinoma (HCC) [14]. As of a different biological behaviour of HCC compared with CRLM and the importance for long-term results in large populations, a meta-analysis for solely CRLM studying both short- and long-term outcomes will add to more careful decision making in elderly patients affected by CRLM.

We performed a systematic review and meta-analysis to investigate the short- and long-term outcomes of liver resection for CRLM in elderly patients.

\section{Methods}

\section{Study Selection}

We adhered to the MOOSE and PRISMA guidelines for reporting on meta-analyses and systematic reviews of observational studies $[15,16]$. A systematic literature search from January 1, 1995 to April 30, 2017 was performed in EMBASE, PubMed and the Cochrane Library.

The PubMed search terms were (elderly*) AND (resection* OR excision* OR surgery* OR surgery [Mesh]) AND (liver* OR liver [Mesh] OR hepatic*) AND (cancer* OR cancer [Mesh] OR malignant* OR malignant [Mesh] OR malignancy* OR malignancy [Mesh] OR metastasis* OR metastasis [Mesh]).

To search EMBASE, the following strategy was used: elderly* AND (resection* OR excision* OR surgery*) AND (liver* OR hepatic*) AND (cancer* OR malignant* OR malignancy* OR metastasis*).

Search terms for the Cochrane Library were elderly* AND (resection* OR excision* OR surgery*) AND (liver* OR hepatic*) AND (cancer* OR malignant* OR malignancy* OR metastasis*).

The search was restricted to title, abstract and keywords. All titles and abstracts of studies identified by the initial search were screened to select those reporting on elderly patients undergoing liver resection. Subsequently, full-text papers of the selected studies were screened independently by 2 authors to assess eligibility.

Included studies had to compare the outcomes of liver resections in "elderly patients" with "younger patients." A recent study defined "elderly" as those 68.5 years of age, as the perioperative risks increase after this age in patients undergoing major gastroin- testinal surgery, like hepatectomy, pancreaticoduodenectomy and esophagectomy [17]. Hence, in an ageing world, with rapidly improving surgical and anaesthetic techniques, even patients over 75 and 80 years of age undergo major gastrointestinal surgery. Therefore, both studies that used a cut-off for "elderly" of 70 years of age, as well studies that used a cut-off of 75 years of age were included in this systematic review. For all studies included, the indication for liver resection had to be CRLM. Studies that included liver resections for other indications and did not report outcomes for CRLM separately were excluded, as were studies that did not report short- and long-term outcomes.

All cross-references were screened for potentially relevant studies not identified by the initial literature search. The final decision on eligibility was reached by consensus.

\section{Data Extraction}

The following variables were extracted from the included studies, if available: baseline characteristics (i.e., number of patients, age, number of lesions, maximum size of lesions), operative characteristics (i.e., operation time, blood loss, histopathological radicality of resection, type of liver resection), complications, in-hospital mortality, total hospital stay, median overall survival, 5-year overall survival, and 5-year disease-free survival.

\section{Assessment of Study Quality}

All included studies were assessed for quality using a validated checklist for methodological quality of non-randomized studies [18]. The MINORS checklist contains 12 items for comparative studies and 8 items for non-comparative studies (maximum of 2 points for each item). A low score represents a high risk of bias, whereas a high score reflects a low risk of bias. None of the studies were excluded on the basis of their score. Baseline characteristics were assessed to determine whether selection bias or confounding by indication might have played a role.

\section{Statistical Analysis}

Statistical analysis was conducted using meta-analysis software (Review Manager, version 5.3. Copenhagen, The Nordic Cochrane Centre, The Cochrane Collaboration, 2011). In the pooled study population, the elderly were compared with non-elderly patients, using weighted mains for continuous variables. Overall survival was analysed using descriptive statistics. Using the MantelHaenszel method, risk ratio's with the 95\% CIs were calculated for the following end points: postoperative morbidity, mortality, 5 -year overall survival and 5-year disease-free survival. A randomeffects model was chosen as the most conservative method. The presence of heterogeneity was assessed using the $I^{2}$ measure, with an $I^{2}$ value greater than 20 indicating heterogeneity. Funnel plots were created to explore possible biases (i.e., reporting, publication and reviewer bias).

\section{Results}

\section{Literature Search}

After removing duplicates, the total number of potential relevant papers was 2,934 . The study selection flowchart is shown in Figure 1. Of the 2,934 papers, 2,920 were 
excluded after reviewing title, abstract or full-text because they reported the following details: non-operative treatment $(n=691)$, non-liver surgery $(n=131)$, other invasive treatment strategies $(n=109)$, scientific meeting reports $(n=59)$, benign liver surgery $(n=25)$, treatment for HCC $(n=444)$, treatment for tumours and metastases of non-colorectal origin $(n=1,068)$, no original patient data $(n=7)$, case report $(n=185)$, literature review $(n=52)$, different age groups $(n=49)$, no data on survival outcome $(n=18)$, no data on outcomes of CRLM separately $(n=$ $3)$, no data on "elderly patients" $(n=75)$ and case series of solely "elderly patients" $(n=4)$.

\section{Included Studies}

Of the 2,934 references, a total of 10 studies were included comparing patients aged $<70$ years with patients aged $>70$ years $[9,10,19-26]$. One additional study was included by checking cross references, taking the total number of included studies to 11 [27]. A total number of 4 studies were included comparing patients aged $<75$ years with patients aged $>75$ years $[12,28-30]$. The characteristics of each study are given in Table 1 . The studies were performed between 1995 and 2016 and comprised of 4 prospective observational cohort studies, 9 retrospective cohort studies, one retro- and prospective cohort study and one case-matched study. The total number of patients in studies comparing patients aged $<70$ years with patients aged $>70$ years was 8,814 for patients aged $<70$ years, whereas the total group of patients $>70$ years comprised of 2,467 patients. In the studies comparing patients aged $<75$ years with patients aged $>75$ years, the total number of patients aged $<75$ years was 2,749, whereas the total number of patients $>75$ years was 385 patients. Follow-up data was available in all but 4 studies, with a median follow-up period between 16 and 48 months.

Assessment on study quality using the MINORS checklist is listed in Table 2. All included studies were of moderate quality.

\section{Studies Comparing Patients Aged $<70$ Years with \\ Patients Aged $>70$ Years \\ Patient Characteristics}

Elderly patients represented between 21 and 33\% of the study population in the different series, indicating that liver resection was performed 3-5 times more often in the younger population. In the pooled patient population, patients aged $>70$ years represent $22 \%$ of the patients. The weighted mean age of patients aged $<70$ years was $58.3 \pm 7.7$ years, whereas the mean age of patients

Liver Resection in the Elderly

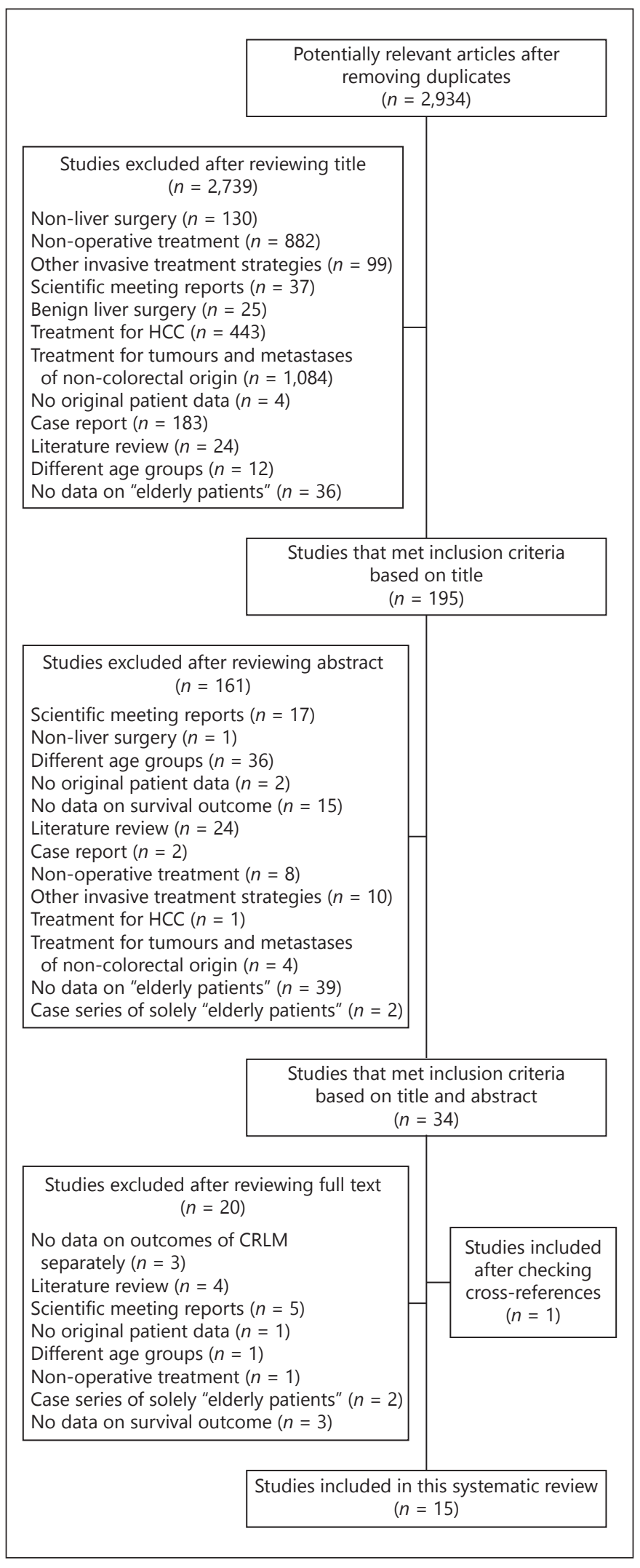

Fig. 1. Flowchart. 
Table 1. Study characteristics

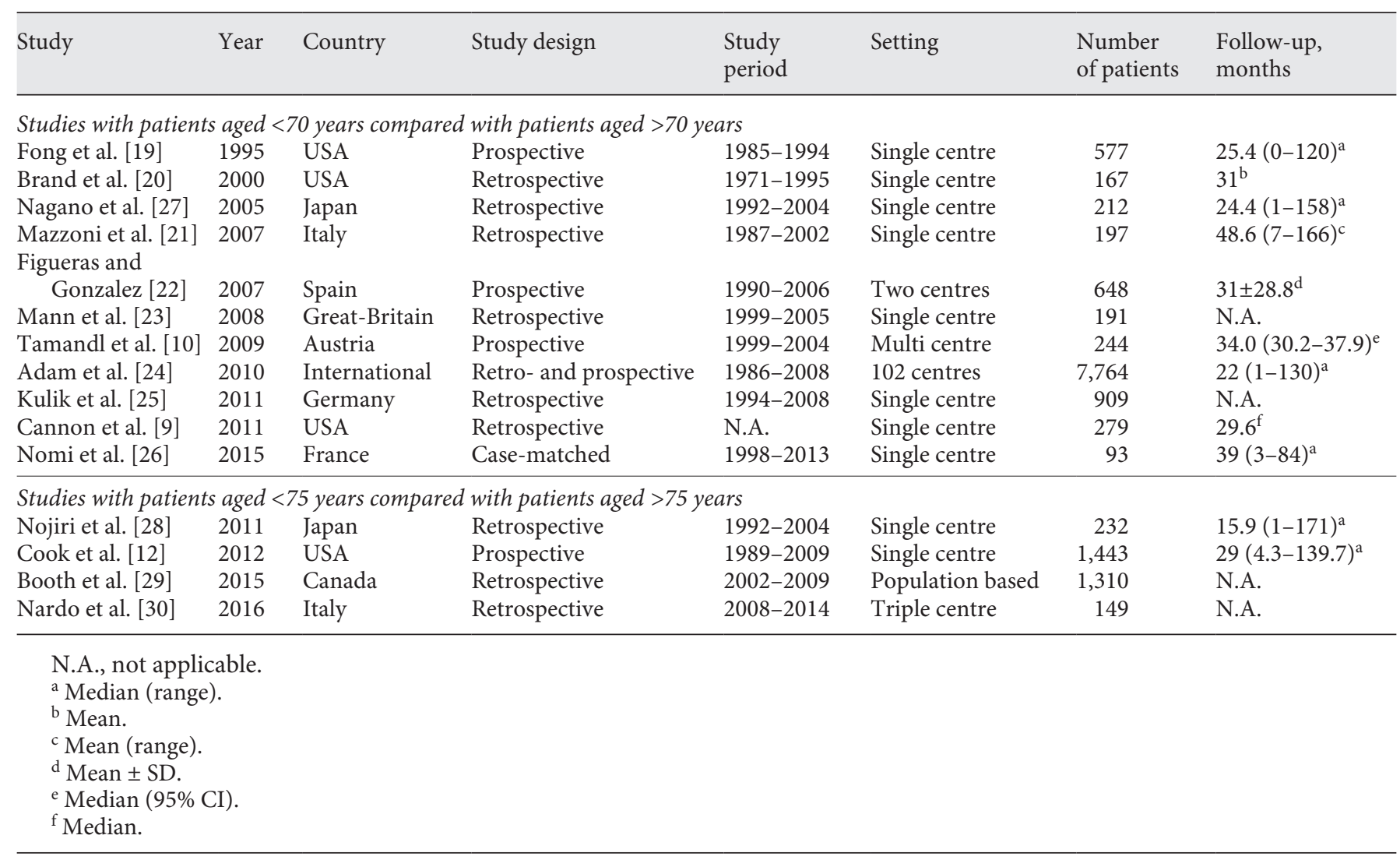

aged $>70$ years was $73.8 \pm 3.2$ years. Data regarding comorbidity was reported in about half the studies reviewed $[19,21,23,26,27]$. Patients aged $<70$ years had less cardiovascular comorbidity ( 12 vs. $36 \%$; $p<0.001$ ), less respiratory comorbidity ( 8 vs. $18 \% ; p=0.01$ ), less hypertension ( 28 vs. $52 \% ; p=0.04$ ) and less diabetes mellitus ( 7 vs. $13 \% ; p=0.02$ ) than patients aged $>70$ years (Table 3 ).

\section{Details of Operations}

Elderly patients underwent significantly less often resection of 3 or more segments (i.e., major hepatectomy; 57 vs. $48 \%$; $p<0.001)$. The weighted mean operative time in patients aged $<70$ years was $295 \pm 101 \mathrm{~min}$ as compared with $279 \pm 95 \mathrm{~min}$ in patients aged $>70$ years $(p=0.004)$. There was no difference in histopathological radicality of the resection between age groups ( 89 vs. $85 \%$; $p=0.61$; Table 4 ).

\section{Postoperative Outcomes}

Most frequently reported complications were abdominal abscess, pneumonia and hepatic failure. Reported morbidity rates varied greatly among all studies - from 12 to $53 \%$. The overall weighted morbidity was $27 \%$ for pa- tients aged $<70$ years and $30 \%$ for patients aged $>70$ years $(p=0.35$; Fig. 2a).

Hospitalization time also varied widely between studies, with one study reporting a mean hospital stay for over 3 weeks [27]. Weighted mean hospital stay in patients aged $<70$ years was $12.6 \pm 11.6$ days compared with $13.2 \pm$ 10.7 days for patients aged $>70$ years $(p=0.19)$.

Postoperative mortality was reported very diversely, differing from a follow-up time of 30 to 90 days postoperative, whereas 6 studies did not report the period of postoperative follow-up [19-21, 25-27]. In the pooled study population, postoperative mortality in patients aged $<70$ years was 2 vs. $4 \%$ in patients aged $>70$ years $(p=$ 0.01; Fig. 2b; Table 5).

\section{Long-Term Survival}

Two studies reported 3-year overall survival results $[24,26]$, one of which reported significantly longer overall survival in patients aged $<70$ years [24]. The pooled mean 5 -year overall survival for patients aged $<70$ years was 40 vs. $32 \%$ for patients aged $>70$ years $(p<0.001$; Fig. $2 c)$. The 5 -year disease free survival was comparable for both 
Table 2.

a. MINORS checklist included studies patients aged $<70$ years

\begin{tabular}{|c|c|c|c|c|c|c|c|c|c|c|c|}
\hline Study & $\begin{array}{l}\text { Fong } \\
\text { et al. } \\
{[19]}\end{array}$ & $\begin{array}{l}\text { Brand } \\
\text { et al. } \\
{[20]}\end{array}$ & $\begin{array}{l}\text { Nagano } \\
\text { et al. } \\
{[27]}\end{array}$ & $\begin{array}{l}\text { Mazzoni } \\
\text { et al. } \\
{[21]}\end{array}$ & $\begin{array}{l}\text { Figueras and } \\
\text { Gonzalez } \\
{[22]}\end{array}$ & $\begin{array}{l}\text { Mann } \\
\text { et al. } \\
{[23]}\end{array}$ & $\begin{array}{l}\text { Tamandl } \\
\text { et al. } \\
{[10]}\end{array}$ & $\begin{array}{l}\text { Adam } \\
\text { et al. } \\
{[24]}\end{array}$ & $\begin{array}{l}\text { Kulik } \\
\text { et al. } \\
{[25]}\end{array}$ & $\begin{array}{l}\text { Cannon } \\
\text { et al. } \\
{[9]}\end{array}$ & $\begin{array}{l}\text { Nomi } \\
\text { et al. } \\
{[26]}\end{array}$ \\
\hline
\end{tabular}

Methodological items for non-randomized studies

A clearly stated aim

Inclusion of consecutive patients

Prospective collection of data

Endpoints appropriate to aim of study

Unbiased assessment of study endpoint

FU period appropriate to aim of study

Loss to $\mathrm{FU}<5 \%$

Prospective calculation of the study size

\begin{tabular}{lllllllllll}
2 & 2 & 2 & 2 & 2 & 2 & 2 & 2 & 2 & 2 & 2 \\
2 & 2 & 2 & 2 & 2 & 2 & 2 & 2 & 2 & 2 & 2 \\
2 & 1 & 1 & 1 & 2 & 1 & 2 & 2 & 1 & 2 & 2 \\
2 & 2 & 2 & 2 & 2 & 2 & 2 & 2 & 2 & 2 & 2 \\
0 & 0 & 0 & 0 & 0 & 0 & 0 & 0 & 0 & 0 & 0 \\
1 & 1 & 1 & 1 & 1 & 0 & 1 & 1 & 0 & 1 & 1 \\
0 & 0 & 2 & 0 & 0 & 0 & 0 & 0 & 0 & 0 & 0 \\
0 & 0 & 0 & 0 & 0 & 0 & 0 & 0 & 0 & 0 & 0 \\
\hline
\end{tabular}

Additional criteria for comparative studies

An adequate control group

Contemporary groups

Baseline equivalence of groups

Adequate statistical analysis

$\begin{array}{rrrrr}2 & 2 & 2 & 2 & 2 \\ 2 & 2 & 2 & 2 & 2 \\ 0 & 2 & 2 & 2 & 2 \\ 2 & 2 & 2 & 2 & 2 \\ 15 & 16 & 18 & 16 & 17\end{array}$

$\begin{array}{rrrrrr}2 & 2 & 2 & 2 & 2 & 1 \\ 2 & 2 & 2 & 2 & 2 & 2 \\ 2 & 2 & 2 & 2 & 2 & 2 \\ 2 & 2 & 2 & 2 & 2 & 2 \\ 15 & 17 & 17 & 15 & 17 & 16\end{array}$

b. MINORS checklist included studies patients aged $<75$ years

\begin{tabular}{|c|c|c|c|c|}
\hline Study & Nojiri et al. [28] & Cook et al. [12] & Booth et al. [29] & Nardo et al. [30] \\
\hline \multicolumn{5}{|c|}{ Methodological items for non-randomized studies } \\
\hline A clearly stated aim & 2 & 2 & 2 & 2 \\
\hline Prospective collection of data & 1 & 2 & 1 & 0 \\
\hline Endpoints appropriate to aim of study & 2 & 2 & 2 & 2 \\
\hline Unbiased assessment of study endpoint & 0 & 0 & 0 & 0 \\
\hline Prospective calculation of the study size & 0 & 0 & 0 & 0 \\
\hline \multicolumn{5}{|l|}{ Additional criteria for comparative studies } \\
\hline An adequate control group & 2 & 2 & 2 & 2 \\
\hline Contemporary groups & 2 & 2 & 2 & 2 \\
\hline Baseline equivalence of groups & 2 & 2 & 2 & 2 \\
\hline
\end{tabular}

groups ( 28 vs. $32 \% ; p=0.55$ ), whereas 3 studies reported 3 -year disease-free survival rates $[10,24,26]$. These studies reported comparable disease-free survival for both groups. Median overall survival is given in Table 5 .

\section{Studies Comparing Patients Aged $<75$ Years with \\ Patients Aged $>75$ Years \\ Patient Characteristics}

Elderly patients represented $10-14 \%$ of the study population in the respective studies. The weighted mean age of patients aged $<75$ years was $61.5 \pm 6.7$ years, whereas the weighted mean age of patients aged $>75$ years was $77.6 \pm 1.6$ years. Only 2 studies reported on comorbidity $[28,30]$, which showed that patients aged $>75$ years were affected more often by cardiovascular comorbidity (33 vs. $20 \% ; p=0.03)$. There was no difference in respiratory comorbidity ( 7 vs. $4 \% ; p=0.58)$ and diabetes mellitus (15 vs. $9 \% ; p=0.19)$ compared with patients aged $<75$ years (Table 3). 
Table 3. Patient characteristics

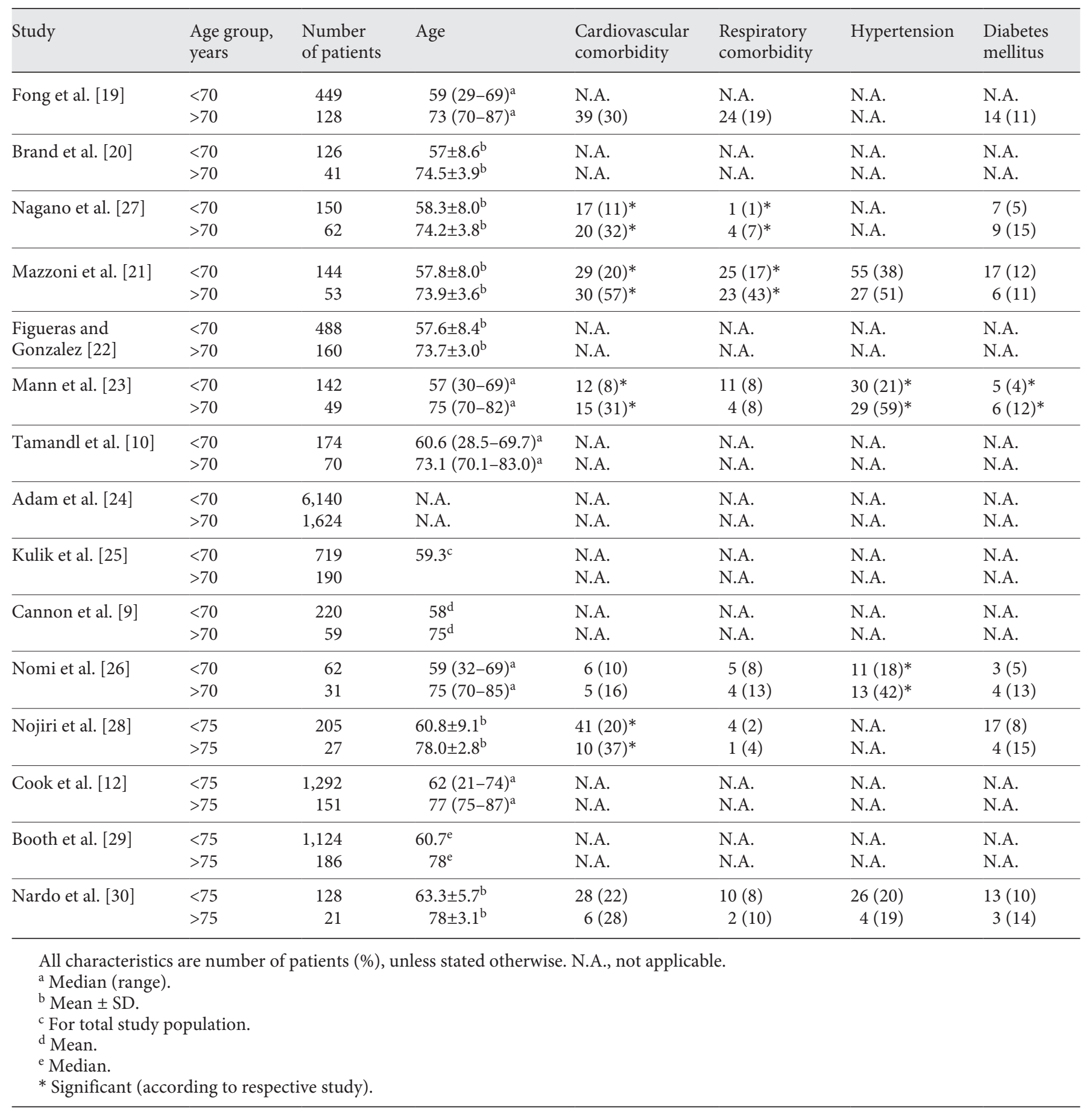

Details of Operations

The weighted mean operative time was $267 \pm 104 \mathrm{~min}$ for patients aged $<75$ years and $260 \pm 108 \mathrm{~min}$ for patients aged $>75$ years $(p=0.62)$. Major hepatectomy was more frequently performed in patients aged $<75$ years $(61 \%)$ compared with patients aged $>75$ years $(53 \% ; p=0.003)$. Only 2 studies reported histopathological radicality $[28$, 29], which showed no differences ( 90 vs. $89 \%$; $p=0.45$; Table 4). 
Table 4. Details of operations

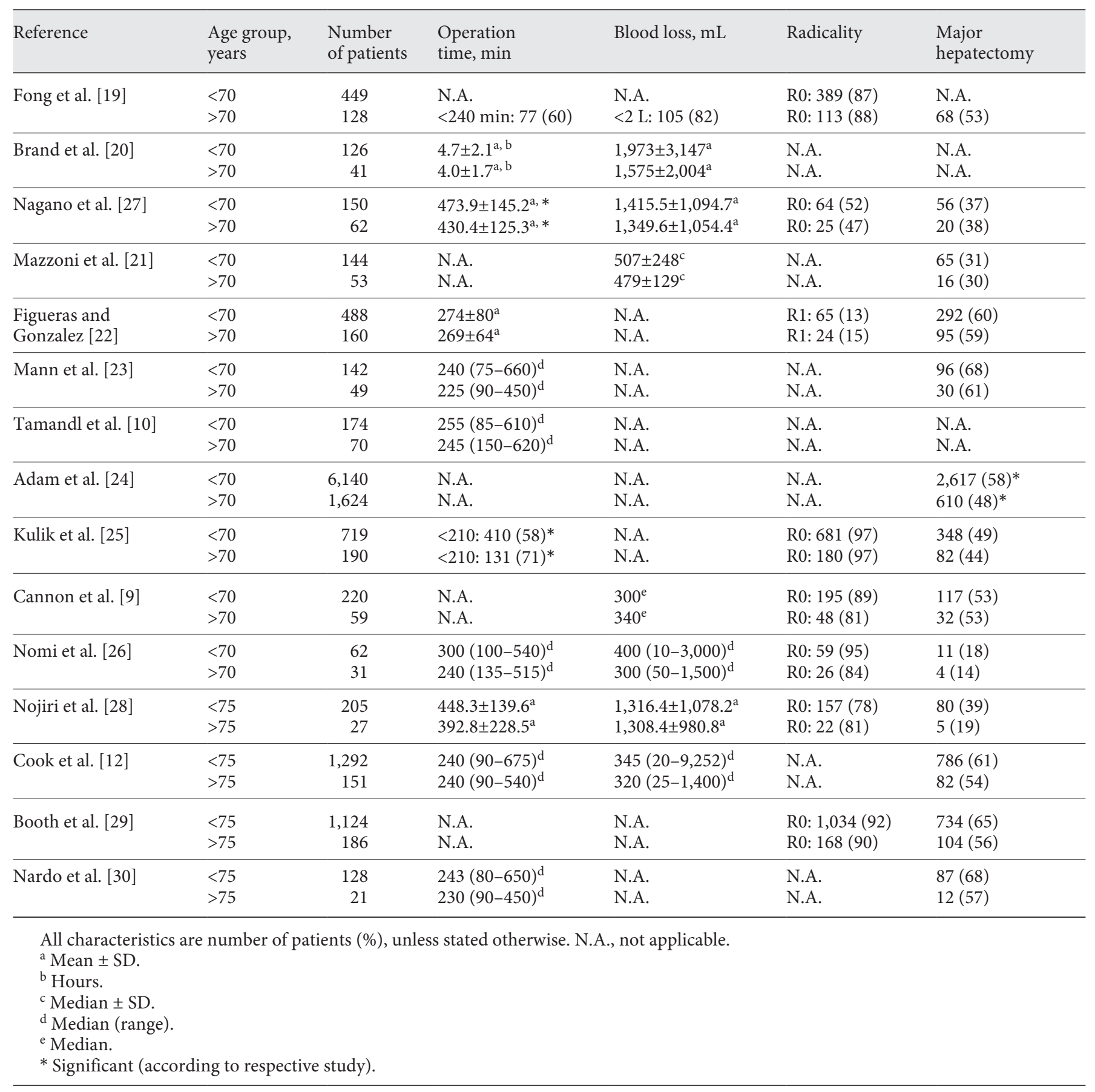

\section{Postoperative Outcomes}

Hospitalisation time varied widely between the respective studies from a mean hospital stay of 6 days to a mean hospital stay of 22 days. Weighted mean hospitalisation time was comparable for patients aged $<75$ years with patients aged $>75$ years $(8.8 \pm 11.6$ vs. $10 \pm 10.1$ days; $p=0.29)$.
Overall postoperative morbidity was reported by 3 studies $[12,28,30]$. The weighted morbidity was $21 \%$ for patients aged $<75$ years compared with $32 \%$ for patients aged $>75$ years $(p=0.001$; Fig. $3 a)$.

Postoperative mortality was defined as mortality within 30 days by 3 studies [28-30] and within 90 days by 


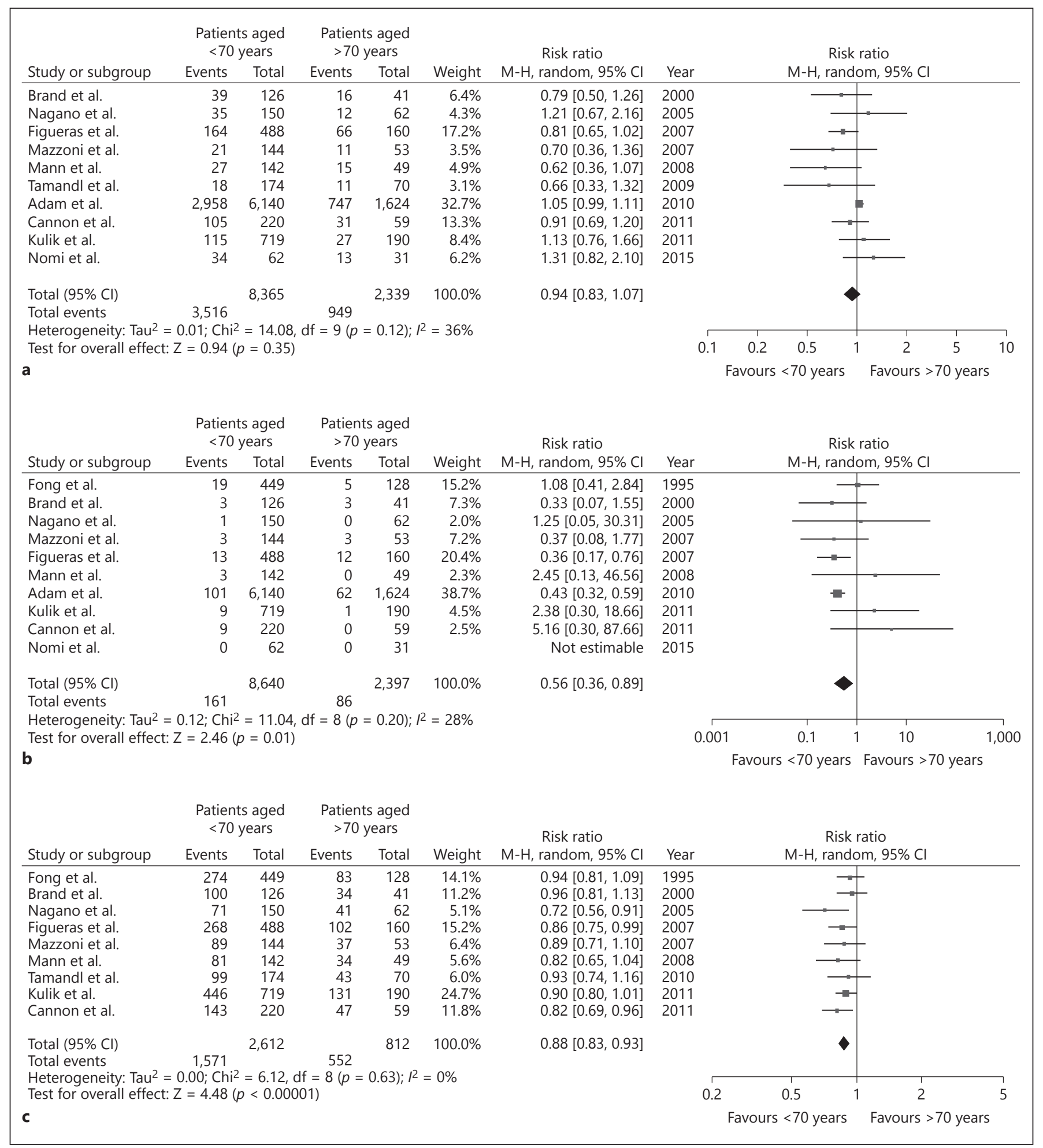

Fig. 2. a Postoperative morbidity for liver resection for CRLM in patients aged $<70$ years and patients aged $>70$ years. b Postoperative mortality for liver resection for CRLM in patients aged $<70$ years and patients aged $>70$ years. c Five-year overall survival for liver resection for CRLM in patients aged $<70$ years and patients aged $>70$ years. CRLM, colorectal liver metastases; $\mathrm{M}-\mathrm{H}$, MantelHaenszel. 
Table 5. Short- and long-term outcomes

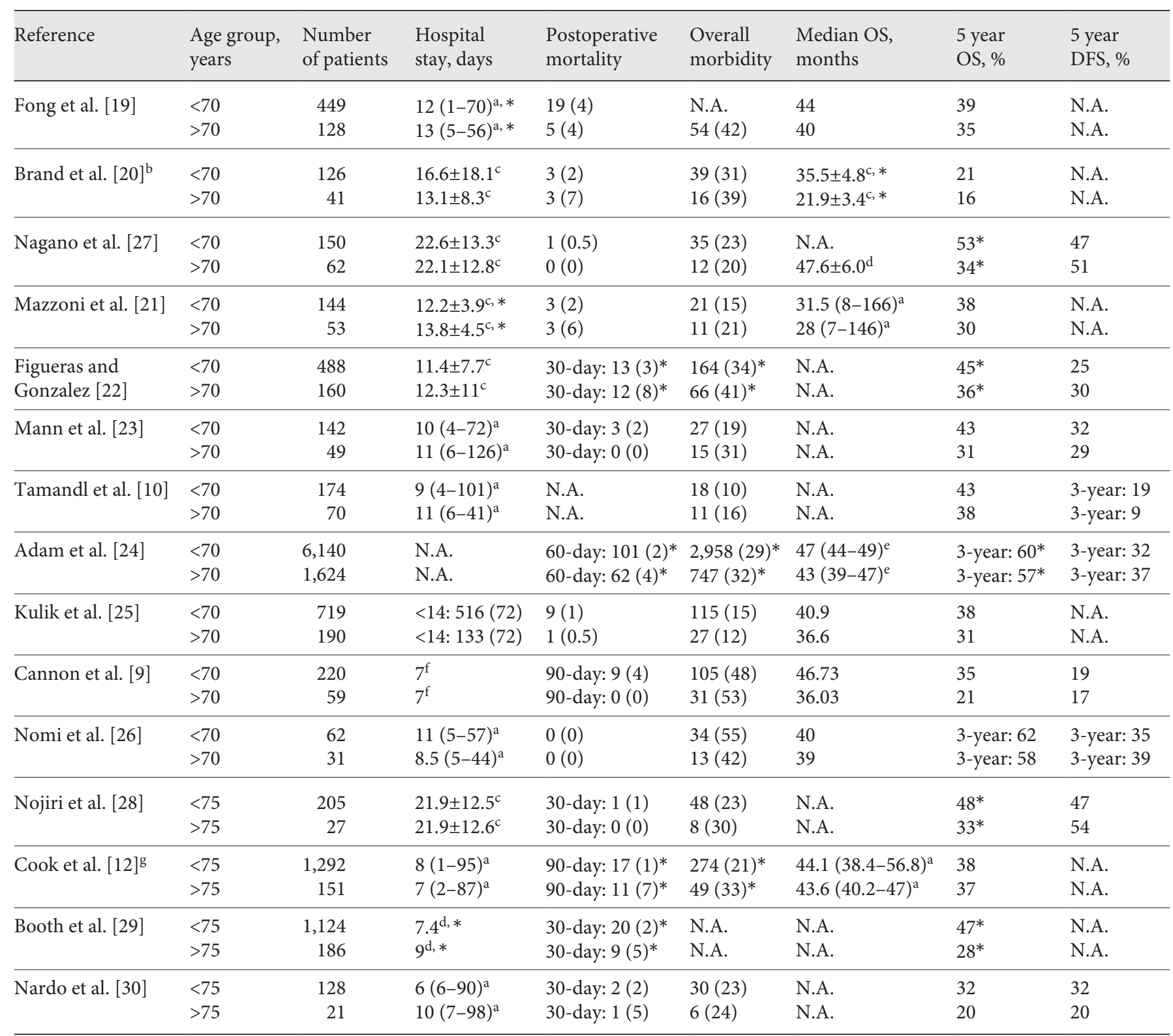

All characteristics are number of patients (\%), unless stated otherwise. N.A., not applicable.

${ }^{\text {a }}$ Median (range).

${ }^{\mathrm{b}}$ Only minor and major morbidity (young vs. old): minor 17 (13\%) vs. 4 (10\%) and major 22 (18\%) vs. 12 (29\%).

${ }^{c}$ Mean \pm SD.

${ }^{\mathrm{d}}$ Median \pm SD.

${ }^{\mathrm{e}}$ Median (95\% CI).

${ }^{\mathrm{f}}$ Median

g Only slight, relevant and life-threatening morbidity (young vs. old): slight 100 (8\%) vs. 18 (12\%), relevant 140 (11\%) vs. 17 (11\%) and life threatening $46(4 \%)$ vs. $16(11 \%)^{*}$.

* Significant (according to respective study). 


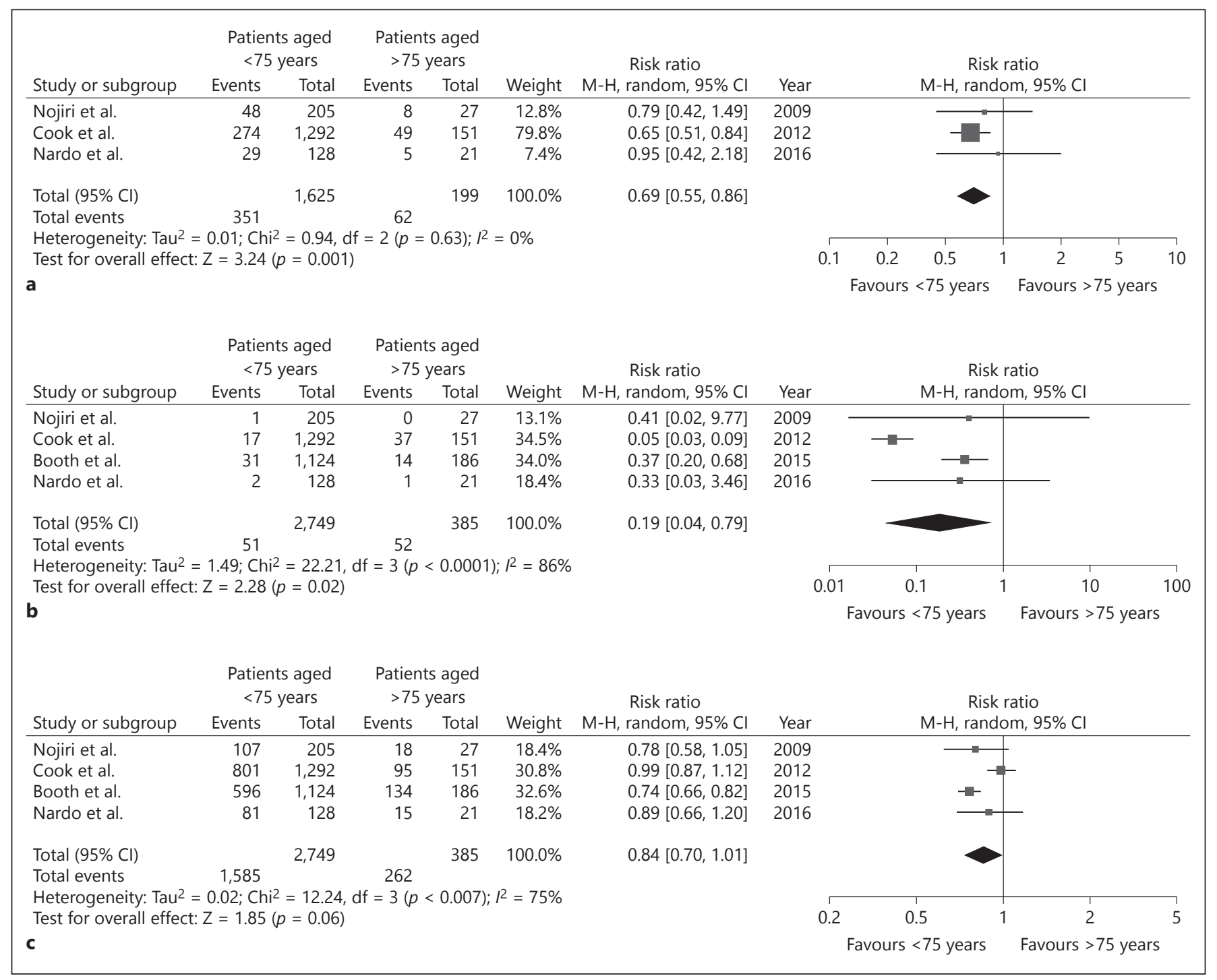

Fig. 3. a Postoperative morbidity for liver resection for CRLM in patients aged $<75$ years and patients aged $>75$ years. b Postoperative mortality for liver resection for CRLM in patients aged $<75$ years and patients aged $>75$ years. $\mathbf{c}$ Five-year overall survival for

1 study [12]. The weighted postoperative mortality for all studies was $1 \%$ for patients aged $<75$ years compared with $6 \%$ in patients aged $>75$ years ( $p=0.02$; Table 5 ; Fig. $3 b)$.

\section{Long-Term Outcome}

All studies reported 5-year overall survival. The pooled mean 5-year overall survival was similar for patients aged $<75$ years compared with patients aged $>75$ years ( 42 vs. $32 \% ; p=0.06$; Fig. 3c). Only 2 studies reported 5-year disease-free survival $[28,30]$. The weighted 5 -year disease-free survival was $41 \%$ for patients aged $<75$ years liver resection for CRLM in patients aged $<75$ years and patients aged $>75$ years. CRLM, colorectal liver metastases; $\mathrm{M}-\mathrm{H}$, MantelHaenszel.

compared with $39 \%$ for patients aged $>75$ years $(p=0.16)$. Only one study reported median overall survival [12], which is given in Table 5 .

\section{Discussion}

This study systematically reviewed the short- and long-term outcomes in elderly patients undergoing liver resection for CRLM. Our main findings were that there were no differences in postoperative morbidity and 5-year 
disease-free survival for patients aged $<70$ years and patients aged $>70$ years. However, postoperative mortality was slightly lower and 5-year overall survival rates were higher for patients aged $<70$ years, as compared with patients aged $>70$ years ( 32 vs. $40 \%$ ). Postoperative morbidity and postoperative mortality both were significantly higher in patients aged $>75$ years compared with patients aged $<75$ years. Postoperative mortality was almost twice as high in patients $>75$ years, as compared with the group of patients $>70$ years. Overall survival and disease-free survival were similar for patients aged $<75$ years, as compared with patients aged $>75$ years.

A recent systematic review and meta-analysis that included 6 studies with patients with CRLM, also showed higher postoperative mortality for patients aged $>70$ years. This study also demonstrated that patients aged $>70$ years more frequently underwent resection of single metastases and less often underwent major hepatectomy. No analysis was done, however, for overall survival [13]. Another recent meta-analysis combining both CRLM as HCC and other malignant liver tumours showed higher mortality for elderly patients but comparable disease-free survival. As for the different malignancies, these results are difficult to interpret for patients who undergo liver resection for CRLM [14]. Therefore, this meta-analysis analyses both short- and long-term outcomes for patients who undergo liver resection for CRLM, as both outcomes are relevant for careful decision making.

As life expectancy is increasing worldwide, the age of patient populations is also increasing. Small single-centre studies comprising patients who undergo liver resection for CRLM have already been performed for very aged patients ( $>80$ years). These small studies suggest potential similar short- and long-term outcomes between patients aged $<80$ years and patients aged $>80$ years $[11,31,32]$.

One of the first potential limitations of liver surgery in elderly patients is the anticipated higher risk for postoperative complications. The current meta-analysis confirmed a higher postoperative mortality for elderly patients as compared with their younger counterparts. This might be explained in part by the fact that advanced age by itself is a risk factor for higher perioperative mortality. However, it is more likely explained by the fact that elderly patients more frequently have coexisting chronic morbidity, as was also shown in this meta-analysis. It should be emphasized that the present data come from more than 100 centres, not limited to only expert institutions. The results are therefore likely to be generalizable to the general patient population. In more specialized centres, complication rates can be lower due to strict pre- operative counselling and close postoperative monitoring [33]. This necessitates a close collaboration between surgeons, anaesthesiologists, cardiologists, pulmonary physicians and geriatric physicians.

The difference in overall survival between elderly and younger patients, only shown in studies comparing patients aged $<70$ years with patients aged $>70$ years, could in part be explained by the more limited survival expectancy of the elderly population. This assumption can be supported by the observation that disease-free survival did not differ between the elderly and younger population. One could therefore assume that older patients die of different causes, making liver resection curative for CRLM. Comorbidity, as stated before, is also an important variable for the physical condition of the patient and therefore the life expectancy.

Age limits are being pushed for various other types of major operations, such as oesophageal and pancreatic surgery, partly because of an increasing health status of the elderly [34-36]. Similarly, an increasing number of elderly patients with good performance status can be considered for hepatectomy. Accordingly, in this meta-analysis, $22 \%$ of patients who had resection of CRLM were at least 70 years old and over $10 \%$ of patients being over 75 years old, making this group of patients a significant part of the population considered suitable for hepatectomy. The number of studies that have recently been published on elderly patients years who undergo hepatectomy support this [11,31,37-39]. Aside from recently published studies regarding liver surgery in elderly patients, older studies were also included in this meta-analysis. Due to changes in supportive perioperative treatment and (neo-)adjuvant chemotherapy during the more recent years, this could have led to sample bias.

Most studies evaluating the outcome after hepatectomy in elderly patients have included non-colorectal malignancies, mostly HCC [40-44]. Due to the different pathophysiology of the tumour and the potential differences between patients, these studies were not included in this systematic review. Also, most studies regarding surgery for CRLM in elderly patients contain small numbers and are single-centre studies [9-12].

Different cut-off points for age of elderly patients limit the comparison of most available studies on liver resection in the elderly. For the current systematic review, we mainly included studies in which "elderly" was defined as a term that denoted people older than 70 years of age. A recent study demonstrated 68.5 years of age to represent the best definition of elderly, as the perioperative risks increase after this age, and more rapidly increases after 
75 years of age in patients undergoing major gastrointestinal surgery, like hepatectomy, pancreatoduodenectomy and esophagectomy [45]. The increase in weighted postoperative morbidity and mortality for patients aged $>75$ years in this study supports this trend; the postoperative mortality almost doubles in patients $>75$ years. A dozen number of studies use even 65 years or even lesser as a cut-off point [46-49], but other studies select patients over $75[50,51]$ or even over 80 years of age $[31,39,52]$.

An important confounder in studies on short- and long term outcomes of liver resections is the administration of neoadjuvant or adjuvant chemotherapy. The included studies in this systematic review used different regimens of (neo)adjuvant chemotherapy $[9,10,12,22$, $24-27,29,30]$ and several studies did not report on the administration of chemotherapy [19-21, 23, 28]. These differences, however, reflect variations in the stage of the disease and the differences between countries, which probably also adds to generalizability.

A limitation of this review is that most included studies did not report comorbidity. Comorbidity differed significantly between patients aged $<70$ years and patients aged $>70$ years in the few studies that reported on comorbidity, as well as cardiovascular comorbidity in patients aged $<75$ years, as compared with patients aged $>75$ years. One could assume that only the relatively physically fit patients were selected for surgery. Relatively physically fit patients aged $>70$ or $>75$ years were, however, still likely to be less physically fit in terms of comorbidity, compared with their younger counterparts.

In conclusion, liver resection for CRLM in patients aged $>70$ years provide similar disease-free survival rates to patients of younger age for a comparable risk for perioperative complications. Perioperative mortality, however, is slightly higher for patients $>70$ years of age and the overall survival rates are lower. In patients aged $>75$ years, perioperative mortality is almost doubled, overall morbidity is higher, but overall survival and disease-free survival are similar for the group of patients aged $>70$ years. The outcomes of this study justify liver resection for CRLM in selected elderly patients affected by CRLM, but caution should be taken in performing hepatectomy in patients aged $>75$ years, given the increase in postoperative morbidity and mortality.

\section{References}

1 Ferlay J, Shin HR, Bray F, Forman D, Mathers C, Parkin DM: Estimates of worldwide burden of cancer in 2008: GLOBOCAN 2008. Int J Cancer 2010;127:2893-2917.

-2 Leporrier J, Maurel J, Chiche L, Bara S, Segol P, Launoy G: A population-based study of the incidence, management and prognosis of hepatic metastases from colorectal cancer. Br J Surg 2006;93:465-474.

-3 Manfredi S, Lepage C, Hatem C, Coatmeur O, Faivre J, Bouvier AM: Epidemiology and management of liver metastases from colorectal cancer. Ann Surg 2006;244:254-259.

4 van der Pool AE, Damhuis RA, Ijzermans JN, de Wilt JH, Eggermont AM, Kranse R, et al: Trends in incidence, treatment and survival of patients with stage IV colorectal cancer: a population-based series. Colorectal Dis 2012; 14:56-61.

$>5$ House MG, Ito H, Gonen M, Fong Y, Allen PJ, DeMatteo RP, et al: Survival after hepatic resection for metastatic colorectal cancer: trends in outcomes for 1,600 patients during two decades at a single institution. J Am Coll Surg 2010;210:744-752, 752-755.

6 Kanas GP, Taylor A, Primrose JN, Langeberg WJ, Kelsh MA, Mowat FS, et al: Survival after liver resection in metastatic colorectal cancer: review and meta-analysis of prognostic factors. Clin Epidemiol 2012;4:283-301.

7 Jarnagin WR, Gonen M, Fong Y, DeMatteo $\mathrm{RP}$, Ben-Porat L, Little S, et al: Improvement in perioperative outcome after hepatic resection: analysis of 1,803 consecutive cases over the past decade. Ann Surg 2002;236:397-406; discussion 406-407.

$\checkmark 8$ Poon RT, Fan ST, Lo CM, Liu CL, Lam CM, Yuen WK, et al: Improving perioperative outcome expands the role of hepatectomy in management of benign and malignant hepatobiliary diseases: analysis of 1222 consecutive patients from a prospective database. Ann Surg 2004;240:698-708; discussion 708-710.

-9 Cannon RM, Martin RC, Callender G, McMasters KM, Scoggins CR: Safety and efficacy of hepatectomy for colorectal metastases in the elderly. Gastroenterology 2011;140: S1051-S1052.

$>10$ Tamandl D, Gruenberger B, Herberger B, Kaczirek K, Gruenberger T: Surgery after neoadjuvant chemotherapy for colorectal liver metastases is safe and feasible in elderly patients. J Surg Oncol 2009;100:364-371.

11 Sheikh AA, Joel AS, Johnson MA, Vimalachandran D: Outcome of colorectal cancer resection in octogenarians. S Afr J Surg 2013; 51:68-72.

12 Cook EJ, Welsh FK, Chandrakumaran K, John TG, Rees M: Resection of colorectal liver metastases in the elderly: does age matter? Colorectal Dis 2012;14:1210-1216.

13 Mizuguchi T, Kawamoto M, Meguro M, Okita $\mathrm{K}$, Ota S, Ishii M, et al: Impact of aging on morbidity and mortality after liver resection: a systematic review and meta-analysis. Surg Today 2015;45:259-270.

14 Phan K, An VV, Ha H, Phan S, Lam V, Pleass $\mathrm{H}$ : Hepatic resection for malignant liver tumours in the elderly: a systematic review and meta-analysis. ANZ J Surg 2015;85:815-822.

-15 Stroup DF, Berlin JA, Morton SC, Olkin I, Williamson GD, Rennie D, et al: Meta-analysis of observational studies in epidemiology: a proposal for reporting. Meta-analysis Of Observational Studies in Epidemiology (MOOSE) group. JAMA 2000;283:2008-2012.

-16 Moher D, Liberati A, Tetzlaff J, Altman DG PRISMA Group: Preferred reporting items for systematic reviews and meta-analyses: the PRISMA statement. PLoS Med 2009;6: e1000097.

-17 Kurian AA, Wang L, Grunkemeier G, Bhayani NH, Swanström LL: Defining 'the elderly' undergoing major gastrointestinal resections: receiver operating characteristic analysis of a large ACS-NSQIP cohort. Ann Surg 2013; 258:483-488.

18 Slim K, Nini E, Forestier D, Kwiatkowski F, Panis Y, Chipponi J: Methodological index for non-randomized studies (minors): development and validation of a new instrument. ANZ J Surg 2003;73:712-716.

19 Fong Y, Blumgart LH, Fortner JG, Brennan MF: Pancreatic or liver resection for malignancy is safe and effective for the elderly. Ann Surg 1995;222:426-434; discussion 434-437. 
20 Brand MI, Saclarides TJ, Dobson HD, Millikan KW: Liver resection for colorectal cancer: liver metastases in the aged. Am Surg 2000;66:412-415; discussion 415-416.

-21 Mazzoni G, Tocchi A, Miccini M, Bettelli E, Cassini D, De Santis M, et al: Surgical treatment of liver metastases from colorectal cancer in elderly patients. Int J Colorectal Dis 2007;22:77-83.

22 Figueras J, Gonzalez HD: Surgery of liver metastases of colorectal cancer. Revis Cancer 2008;22:19-27.

23 Mann CD, Neal CP, Pattenden CJ, Metcalfe MS, Garcea G, Dennison AR, et al: Major resection of hepatic colorectal liver metastases in elderly patients - an aggressive approach is justified. Eur J Surg Oncol 2008;34:428432.

24 Adam R, Frilling A, Elias D, Laurent C, Ramos E, Capussotti L, et al: Liver resection of colorectal metastases in elderly patients. $\mathrm{Br} \mathrm{J}$ Surg 2010;97:366-376.

-25 Kulik U, Framke T, Grosshennig A, Ceylan A, Bektas H, Klempnauer J, et al: Liver resection of colorectal liver metastases in elderly patients. World J Surg 2011;35:2063-2072.

26 Nomi T, Fuks D, Kawaguchi Y, Mal F, Nakajima Y, Gayet B: Laparoscopic major hepatectomy for colorectal liver metastases in elderly patients: a single-center, case-matched study. Surg Endosc 2015;29:1368-1375.

-27 Nagano Y, Nojiri K, Matsuo K, Tanaka K, Togo S, Ike H, et al: The impact of advanced age on hepatic resection of colorectal liver metastases. J Am Coll Surg 2005;201:511516.

28 Nojiri K, Nagano Y, Tanaka K, Matsuo K, Yamagishi S, Ota M, et al: Validity of hepatic resection of colorectal liver metastases in the elderly (75 years and older). Anticancer Res 2009;29:583-588.

29 Booth CM, Nanji S, Wei X, Mackillop WJ: Management and outcome of colorectal cancer liver metastases in elderly patients: a population-based study. JAMA Oncol 2015;1: 1111-1119.

30 Nardo B, Serafini S, Ruggiero M, Grande R, Fugetto F, Zullo A, et al: Liver resection for metastases from colorectal cancer in very elderly patients: new surgical horizons. Int J Surg 2016;33(suppl 1):S135-S141.
Riffat F, Chu F, Morris DL: Liver resection in octogenarians. HPB (Oxford) 2006;8:206210.

32 Nakamura T, Sato T, Miura H, Ikeda A, Tsutsui A, Naito M, et al: Feasibility and outcomes of surgical therapy in very elderly patients with colorectal cancer. Surg Laparoscopy Endosc Percutaneous Tech 2014;24: 85-88.

33 Fernandez FG, Drebin JA, Linehan DC, Dehdashti F, Siegel BA, Strasberg SM: Five-year survival after resection of hepatic metastases from colorectal cancer in patients screened by positron emission tomography with F-18 fluorodeoxyglucose (FDG-PET). Ann Surg 2004;240:438-447; discussion 447-450.

34 Markar SR, Smith I, Low D: The clinical and economic costs of delirium following surgical resection for oesophageal malignancy. Gut 2012;61:A310-A311.

35 Markar SR, Karthikesalingam A, Thrumurthy S, Ho A, Muallem G, Low DE: Systematic review and pooled analysis assessing the association between elderly age and outcome following surgical resection of esophageal malignancy. Dis Esophagus 2013;26:250-262.

36 Sukharamwala P, Thoens J, Szuchmacher M, Smith J, DeVito P: Advanced age is a risk factor for post-operative complications and mortality after a pancreaticoduodenectomy: a meta-analysis and systematic review. HPB (Oxford) 2012;14:649-657.

37 de Liguori Carino N, van Leeuwen BL, Ghaneh P, Wu A, Audisio RA, Poston GJ: Liver resection for colorectal liver metastases in older patients. Crit Rev Oncol Hematol 2008; 67:273-278.

38 De'Liguori Carino N: Liver surgery - liver resection for colorectal liver metastases in older patients. Eur J Surg Oncol 2010;36:845.

-39 Shirabe K, Kajiyama K, Harimoto N, Gion T, Tsujita E, Abe T, et al: Early outcome following hepatic resection in patients older than 80 years of age. World J Surg 2009;33:19271932.

-40 Aldrighetti L, Arru M, Caterini R, Finazzi R, Comotti L, Torri G, et al: Impact of advanced age on the outcome of liver resection. World J Surg 2003;27:1149-1154.

41 Aldrighetti L, Arru M, Catena M, Finazzi R, Ferla G: Liver resections in over-75-year-old patients: Surgical hazard or current practice? J Surg Oncol 2006;93:186-193.
42 Menon KV, Al-Mukhtar A, Aldouri A, Prasad RK, Lodge PA, Toogood GJ: Outcomes after major hepatectomy in elderly patients. J Am Coll Surg 2006;203:677-683.

43 Cho SW, Steel J, Tsung A, Marsh JW, Geller DA, Gamblin TC: Safety of liver resection in the elderly: how important is age? Ann Surg Oncol 2011;18:1088-1095.

44 de la Fuente SG, Bennett KM, Scarborough JE: Functional status determines postoperative outcomes in elderly patients undergoing hepatic resections. J Surg Oncol 2013;107: 865-870.

45 Kurian AA, Wang L, Grunkemeier G, Bhayani NH, Swanstrom LL: Defining 'the elderly' undergoing major gastrointestinal resections: receiver operating characteristic analysis of a large ACS-NSQIP cohort. Ann Surg 2013; 258:483-488.

46 Chiappa A, Zbar AP, Biella F, Crotti C, Staudacher C: Validity of hepatic resection for cancer in the elderly. Ann Ital Chir 2002;73: 397-401.

47 Ijtsma AJ, Boeve LM, van der Hilst CS, de Boer MT, de Jong KP, Peeters PM, et al: The survival paradox of elderly patients after major liver resections. J Gastrointest Surg 2008; 12:2196-2203.

48 Robertson DJ, Stukel TA, Gottlieb DJ, Sutherland JM, Fisher ES: Survival after hepatic resection of colorectal cancer metastases: a national experience. Cancer 2009;115: 752-759.

49 Booth CM, Nanji S, Wei X, Mackillop WJ Management and outcome of colorectal cancer liver metastases in elderly patients: a population-based study. JAMA Oncol 2015; 1 : 1111-1119.

50 Bockhorn M, Sotiropoulos GC, Sgourakis G, Neuhaus JP, Molmenti EP, Lang H, et al: Major liver resections in the elderly-is an aggressive approach justified? Int J Colorectal Dis 2009;24:83-86.

51 Schmidt T, Strowitzki MJ, Reissfelder C, Rahbari NN, Nienhueser H, Bruckner T, et al: Influence of age on resection of colorectal liver metastases. J Surg Oncol 2015;111:729-739.

52 Bhandari RS, Riddiough G, Muralidharan V, Christophi C: Early outcome of liver resections in octogenarians. Kathmandu Univ Med J (KUMJ) 2015;13:19-23. 